\title{
Physical Properties of Frozen Ewe's Cheese
}

\author{
Paula M. R. Correia ${ }^{1}$, Melania Correia Rodrigues ${ }^{2}$, Rita Mendes ${ }^{3}$, and Raquel P. F. Guiné ${ }^{1}$ \\ ${ }^{1}$ CI\&DETS/CERNAS, Department of Food Industry, Polytechnic Institute of Viseu, Viseu, Portugal \\ ${ }^{2}$ Department of Food Industry, Agrarian School of Viseu, Viseu, Portugal \\ ${ }^{3}$ Lacticínios Correia \& Barreiras, Seia, Portugal \\ Email: \{paularcorreia, mcrodrigues12, lcb.lda\}@ hotmail.com, raquelguine@esav.ipv.pt
}

\begin{abstract}
This work evaluates the effect of freezing and storage time in ewe's cheese. Ewe's cheeses were subject to two different conservation conditions: frozen at $-60^{\circ} \mathrm{C}$, with storage at $-18^{\circ} \mathrm{C}$ (Frozen), and refrigeration at $7^{\circ} \mathrm{C}$, with a RH (relative humidity) of $47 \%$ (Control). The initial values of moisture and water activity $\left(a_{w}\right)$ were high and similar between the analysed samples, 62.2-61.3\% and 0.91-0.92 respectively, with a decrease of moisture during the storage, being lower in the Frozen sample. The cheeses presented a light colour $\left(L^{*}=69.0\right.$ and 74.6), which decreased during storage. The $a^{*}$ and $b^{*}$ coordinates showed negative and positive values, respectively, meaning that the predominant colours were green and yellow, and generally during storage they diminished. The texture of cheeses, in the first day of storage, presented similar values for Control and Frozen cheeses: 9.8 and $9.9 \mathrm{~N}$ for crust firmness; 3.6 and 3.9 $\mathrm{N}$ for flesh firmness; $\mathbf{- 2 . 6}$ and $\mathbf{- 2 . 8} \mathrm{N}$ for stickiness; $\mathbf{- 2 2 . 7}$ and $\mathbf{2 4 . 7}$ N.sec for adhesiveness. Finally, after 120 days of storage for these cheeses, the crust firmness, the stickiness and the adhesiveness decreased more about three times.
\end{abstract}

Index Terms - ewe's cheese, conservation, frozen, physical properties, colour, textural characteristics

\section{INTRODUCTION}

Ewe's cheese produced in Seia, a district of Portugal, is a traditional cured cheese, usually with a semisoft buttery paste, slightly yellow or white, obtained by slowly draining the curd after coagulation of raw sheep milk achieved by means of thistle flower (Cynara cardunculus). The production process is equal to the Serra da Estrela cheese, a PDO product (Protected Designation of Origin). The ewe's cheese can be produced by small enterprises, which usually use a handmade process, or by medium factories which apply the same steps of handmade production but using specific equipment to obtain a traditional ewe's cheese. Furthermore, properties such as moisture content, fat, protein, cheese form, crust characteristics and pulp consistency are typical and result from the type of milk used as well as from the specific manufacture and cure processes [1], [2].

The cheese from this region commonly has a low regular cylinder form with slight bulging on the sides, and without sharp edges. It possesses a creamy and a well-connected consistency of crumb, with a buttery

Manuscript received March 1, 2018; revised August 10, 2018. texture, and the aroma is smooth and sometimes slightly acid. The texture, flavour and aroma of cheese are associated with the chemical composition and $\mathrm{pH}$, as well as with microstructure [3], [4].

The first indicator of food quality, and mainly in cheeses, is colour. Colour is the first sensation, the most immediate characteristic evaluated by consumers, and it is used as a tool to accept or reject food. Thus, it is essential for the acceptance of the product by consumers, even before tasting [5].

Another important characteristic to consider is the texture of cheese, and, although having a degree of subjectivity, is the principal quality attribute of this foodstuff. Several factors may contribute to the final texture during manufacture. The international standards organization defines texture of food products as "All rheological and structural attributes of the product perceptible by means of mechanical, tactile and, when appropriate, visual and auditory receptors" [6].

The use of different conservation methods to increase the shelf life of food has always been a major concern of humankind. There are some concerns related to the conservation of cured cheeses (soft, semi-soft, hard) of small ruminants (sheep and goat), because problems often appear in the commercialization phase leading to sales' breaks and loss of product, thus loss of profits and losses which could put the business at risk. Furthermore, the manufacture of this type of chesses is related to the seasonal availability of ovine milk, and hence it usually takes place on a limited period, from December to May. These situations were identified by producers, associations, cooperatives and industrials of milk and cheese sectors [7].

Freezing of foods helps to preserve their shelf-life, nutritive value, the colour characteristics, and flavour. However, this conservation method also brings some physical and organoleptic changes, which may or may not be desirable [8]. There are several studies related with the application of freezing process in cheeses, and the majority are related with the Cheddar and Mozzarella cheeses [8]-[12]. These studies indicate that freezing, thawing, and frozen storage modify the physical properties of cheeses. Moreover, cheese is a complex system where several reactions could take place during the storage processes [13].

After an exhaustive research of application and innovation studies regarding the conservation of cheeses produced with ewe's milk, they are very reduced or 
inexistent even in an international dimension. A work was carried out about the freezing process applied to Serpa soft cheese, a PDO ewe's cheese from the South of Portugal, and the results allowed to conclude that it is possible to freeze this type of cheese at a temperature of $20^{\circ} \mathrm{C}$, preserving its specific characteristics, and the type of freezing did not influence its properties [14]. There are some authors that mention the used of low temperature conservation and storage processes (refrigeration and freezing), but not for ewe's cheeses [15]. The results of these studies also showed that the freezing temperatures retain most of the cheeses' quality parameters during storage periods.

The aim of this work was to evaluate the effect of freezing on physical properties of ewe's cheeses in the beginning of storage and after 120 days, comparing with cheeses kept at storage conditions like the commercial ones used.

\section{MATERIALS AND METHODS}

\section{A. Samples}

Cheeses were produced by industrial manufacture from raw ewe's milk produced by animals of breeds Bordaleira Serra da Estrela and Churra Mondegueira, in Seia district. The milk was coagulated using thistle flower (Cynara cardunculus L.), without addition of a starter, and cheeses were maturated for 45 days. The produced cheeses were semi-soft and they were produced in Lacticínios Correia $\&$ Barreiras enterprise. To evaluate the effect of low temperatures in sheep cheese, eight cheeses of the same lot were evaluated according to the distribution presented in Table I, four cheeses were frozen $\left(-60^{\circ} \mathrm{C}\right)$ and kept in a freezer at a temperature range from $-21^{\circ} \mathrm{C}$ to $-18^{\circ} \mathrm{C}$, and the other four cheeses were kept in the refrigerator $\left[7.3 \pm 0.3^{\circ} \mathrm{C}\right.$ and Relative Humidity (RH), of approximately $47 \%$ ], simulating the commercial storage of cheeses. The cheeses were analysed in two different moments. The first moment was the first day of arrival for the Control sample, and one day after freezing, as fo all other samples. The frozen samples were thawed one day in the cooler (approximately $7^{\circ} \mathrm{C}$ ), as recommended by the Regulation CE n. ${ }^{\circ}$ 852/ 2004, until complete thawing. Before the measurement of any characteristic evaluated, cheeses were maintained during about 8 hours at room temperature (approximately $18^{\circ} \mathrm{C}$ ). The second moment was after 120 days of storage.

TABLE I. Number OF CHEESES By CONSERVATION METHOD

\begin{tabular}{|l|c|c|}
\hline Conservation Method & Day of analysis & Number of samples \\
\hline \multirow{2}{*}{ Control } & day 0 & 2 \\
\cline { 2 - 3 } & 120 days & 2 \\
\hline \multirow{2}{*}{ Freezing } & $1^{\text {st }}$ day & 2 \\
\cline { 2 - 3 } & 120 days & 2 \\
\hline
\end{tabular}

\section{B. Physical Properties of Cheeses}

The weight and diameter of each cheese were evaluated (Fig. 1).

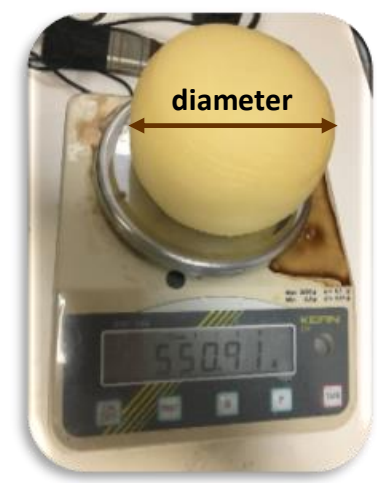

Figure 1. Weight and diameter of evaluated cheeses in initial state.

Moisture content was accessed by mass loss until constant weight in a Halogen Moisture Analyser (Mettler Toledo HG53), set at an operating temperature of $120^{\circ} \mathrm{C}$. Water activity was determined by a hygrometer (Rotronic), at $25^{\circ} \mathrm{C}$. At least 3 determinations of each parameter were done in each cheese.

\section{Colour Evaluation}

The colour parameters were evaluated instrumentally using a colourimeter Chroma Meter (Konica Minolta) (Fig. 2), and the results are expressed in CIELab coordinates defined by the Commission Internationale de l'e'clairage_-'CIE L*a* b* Colour Space', where L* is the lightness of the sample, and ranges from 0 (black) to 100 (white), $a^{*}$ ranges from -60 (green) to +60 (red) and $\mathrm{b}^{*}$ ranges from -60 (blue) to +60 (yellow) [16]. The $\mathrm{L} * \mathrm{a} * \mathrm{~b} *$ coordinates were measured in the rind of the cheese. Ten measurements were made on the upper face and another 10 on the lower face, resulting in 20 measurements performed on each cheese.

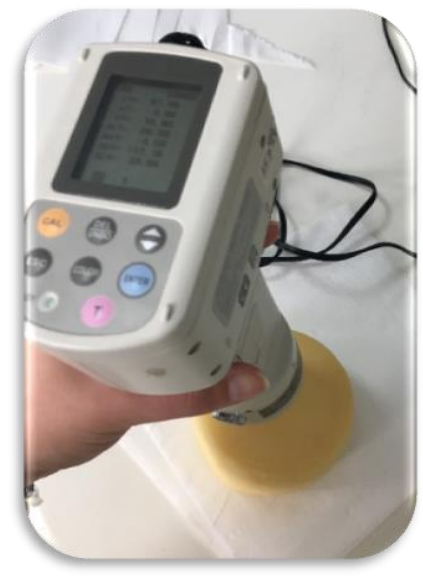

Figure 2. Example of a colour measurement of cheeses.

\section{Texturel Analysis}

For the analysis of textural properties, it was used a texturometer TA-XT2 (Stable Microsystems, UK). With a $2 \mathrm{~mm}$ diameter probe. The test parameters were:

- Test speed: $1.0 \mathrm{~mm} / \mathrm{s}$;

- Distance: $10 \mathrm{~mm}$;

- Acquisition rate: 50 readings taken per second;

- Temperature: $20^{\circ} \mathrm{C}$ 
Whole cheeses were used for the tests and three perforations were made in each sample, distributed on the upper and bottom surfaces of the cheese.

The textural properties evaluated were crust firmness (softness), flesh firmness, adhesiveness and stickiness (Fig. 3).
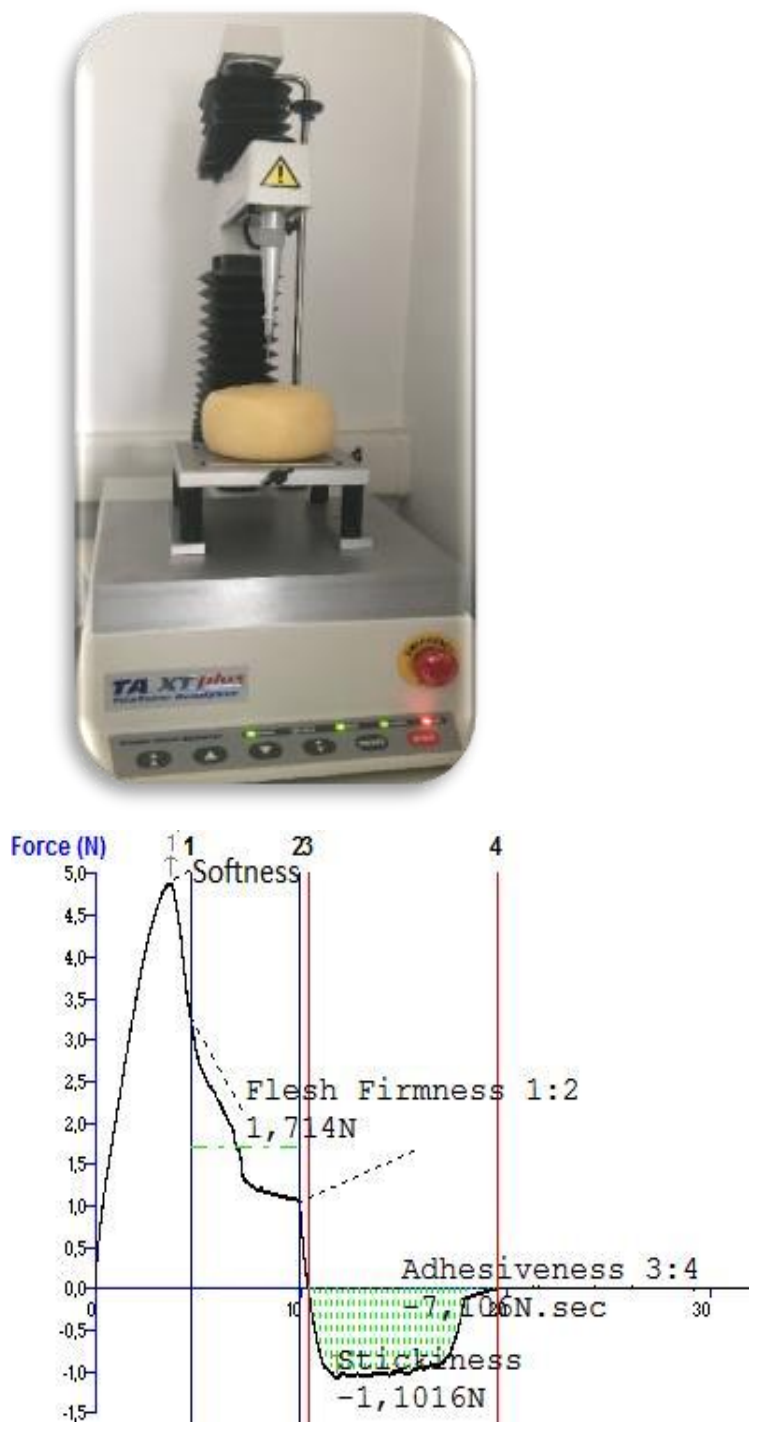

Figure 3. Example of a texture analysis performed to a cheese.

\section{RESULTS AND DISCUSSION}

\section{A. Physical Properties of Cheeses}

The results of weight and diameter of ewe's cheeses are showed in Fig. 4. These determinations were done in the first day of arrival of the cheeses, before their submission to the conservation process, to determine their uniformity. It is possible to notice that the evaluated cheeses are quite similar in weigh and diameter, with an average of $519.7 \mathrm{~g}$ and $11.2 \mathrm{~cm}$ respectively. These results are advantageous since these parameters will not interfere in the results, meaning that the cheeses are quite similar considering the weight and diameter.

The moisture and water activity $\left(\mathrm{a}_{\mathrm{w}}\right)$ are important factors for food storage. The results showed that moisture content and water activity values were quite high (Fig. 5). The moisture and $\mathrm{a}_{\mathrm{w}}$ contents were similar for cheeses before conservation, with values of 62.2-61.3\% and 0.91-0.92 respectively. Thus, the results showed that the water present is available to react with other components of the cheese matrix and the development of microorganisms is a possible concern.

Generally, semi-hard cheeses present high water activities. This parameter influences microbiological and physicochemical evolution of cheeses over the time [17].

Moreover, the control of $\mathrm{a}_{\mathrm{w}}$ and moisture is important for the preservation of safety and quality of cheeses [13].

After 120 days, the water activity did not vary significantly, and the moisture content decreased, mainly in the control sample, which was storage in the refrigerator, simulating the commercial conditions. This diminishment was due probably to some dehydration of the samples during the freezing and refrigeration storage. This phenomenon happens because the mean RH in the cool environment is lower than in the samples, and this is corroborated by the refrigerator $\mathrm{RH}$, which was $47 \%$ during the 120 days of storage. Furthermore, in unpackaged cheese, water loss depends on the chemical properties of the cheeses and on the storage conditions [13].

Furthermore, these two factors are important in food storage, according to Neto et al. [18] most of the microorganisms grow in the range 0.90 to 0.99 (high values of $\mathrm{a}_{\mathrm{w}}$ ), and hence the studied cheeses may be susceptible to the growth of undesirable microorganisms. Corroborating this, it was noticed that during storage, the cheeses conserved in the refrigerator were cleaned several times to remove a few molds in their surfaces. This procedure allowed to keep the cheeses in good conditions.
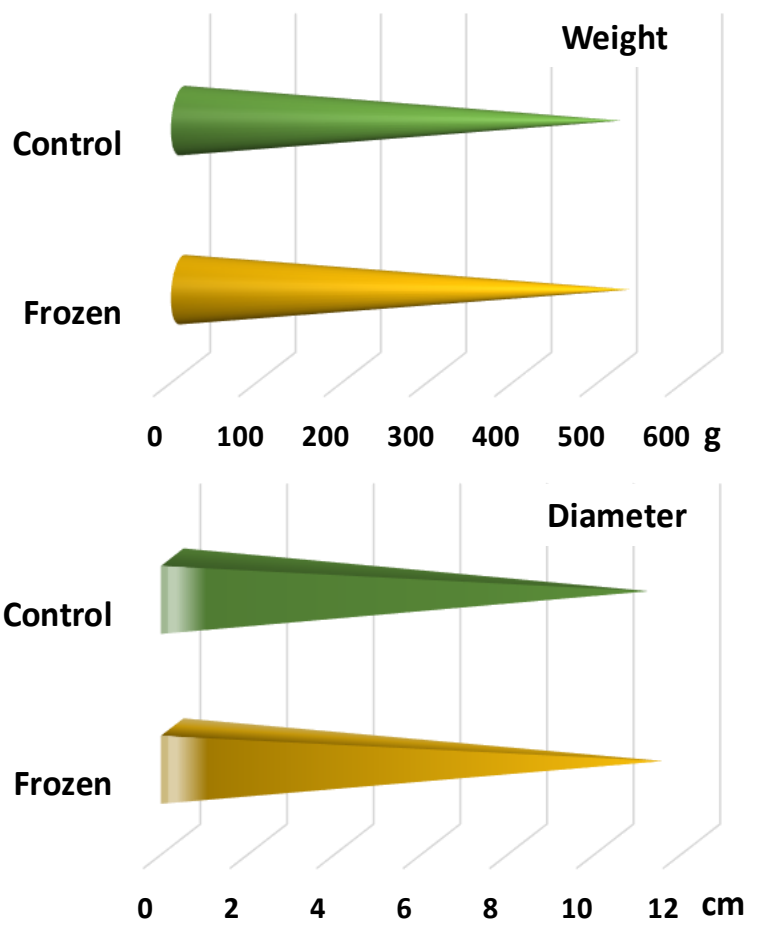

Figure 4. Weight and diameter of evaluated cheeses in initial state. 

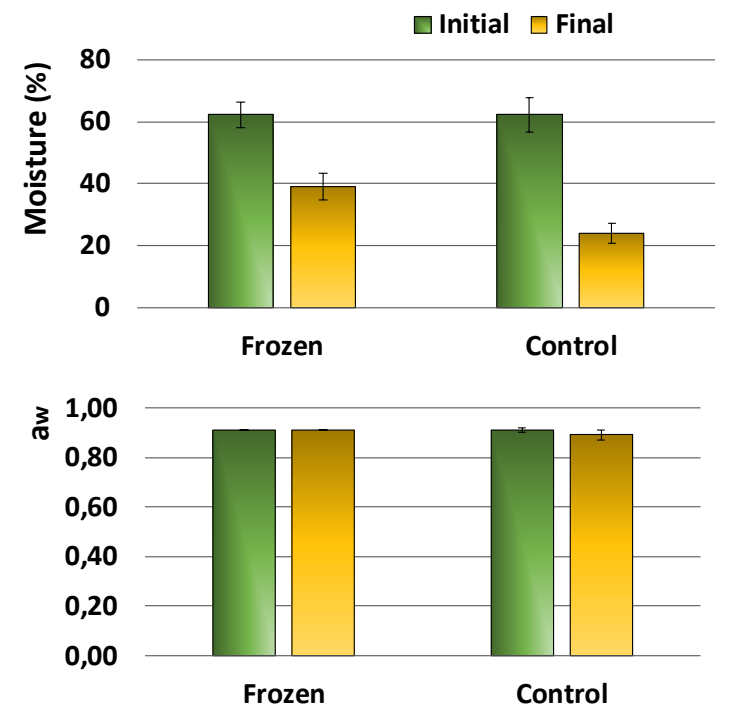

Figure 5. Moisture and water activity (aw) of cheeses in the initial and final stage of the conservation process (120 days).

\section{B. Colour Evaluation}

Colour coordinates are shown in Fig. 6. Generally, the Control and the Frozen samples presented similar behavior, with changes in colour parameters after 120 days of storage, more evident in the Frozen cheeses.

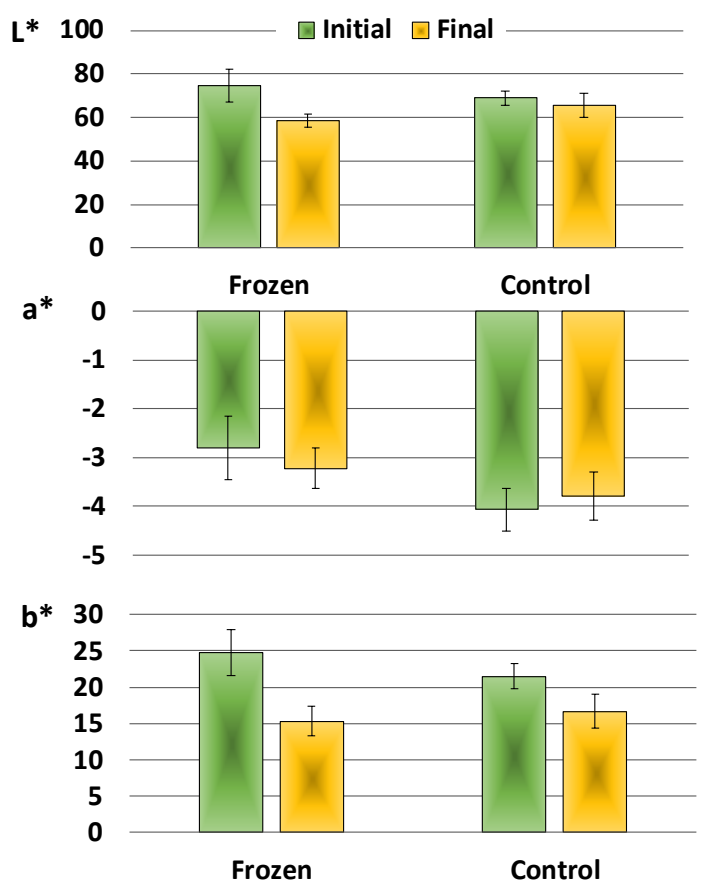

Figure 6. Colour parameters of cheeses in the initial and final stage of storage.

The values obtained for the colour coordinate $\mathrm{L}^{*}$, which represents lightness, varying from 0 (black) to 100 (white), mean that the analysed cheeses presented a light colour in the initial phase of storage. After 120 days of storage, this colour parameter decreased, and this behavior was more evident in the Frozen cheeses, meaning that the skin colour lost whiteness tending to acquire a straw-yellow colouration. These values are in the same range as those reported by several authors also for similar DPO ewe' cheese produced in the same geographical area, the Serra da Estrela cheese, a similar ewe's cheese [19], [20].

The colour coordinate $a^{*}$, which represents green for negative values and red for positive, showed negative values, indicative of a very slight green colouration, which is also corroborated for other ewe's cheeses [19], [20]. As to the influence of storage in colour, a moderate decrease was found in the Control samples, indicating that the cheeses became less green. In opposition, the Frozen cheeses presented a slight increase of the values for a* coordinate, becoming greener.

The values for colour coordinate $b^{*}$, which represents blue colour when negative and yellow when positive, in the present case are positive, and this coordinate is higher in frozen cheeses in the initial phase of storage. The values for $b^{*}$ obtained by [19] also for Serra da Estrela cheese varied in the range 17-35. After 120 days of storage, the values of $b^{*}$ coordinate diminished in both samples, meaning that cheeses became less yellow.

\section{Textural Analysis}

A typical texture profile obtained for a sample of ewe's cheese is presented in Fig. 3, with indication of the meaning of the textural parameters evaluated [20]:

- Crust firmness - force at the highest peak, representing the force required between the molars for chewing a food;

- Flesh firmness - mean force when perforating the inner part of the cheese, is an indicator of whether the cheese is more or less creamy, together with adhesiveness and stickiness;

- Stickiness - lowest negative value, and it is related to the creaminess of the paste;

- Adhesiveness s- area of the negative curve, representing the force required to remove the material that adheres to a specific surface, such as lips, palate or teeth.

Fig. 7 showed the textural properties evaluated for the cheeses at study. In a general point of view, at the first day of storage the Control and the Frozen samples presented similar tendencies, presenting similar values for firmness, stickiness and adhesiveness. These results mean that a short period of freezing did not affect significantly the textural properties of ewe's cheeses.

The values obtained for crust firmness in the first day of storage were 9.9 and $9.8 \mathrm{~N}$, for Control and Frozen samples, respectively, but in the end of 120 days of storage the crust firmness parameter presented a lower value for the Frozen sample. This could mean that the freezing treatment could change the crust structure of the cheese, and in this case the crust of cheese required less force for chewing. Furthermore, it is quite advantageous that the rind should be strong enough to support the weight of the cheese, acting as its protection, since these cheeses are typically sold without package and hence without any further protection [20]. Thus, the decrease of the crust firmness could be a negative parameter, which 
could compromise the cheese quality during commercial trade.

On the other hand, the flesh firmness also had a significative change during the storage time, in both samples. At the end of 120 days the values found were similar for both cheese samples, 1.0 and $1.1 \mathrm{~N}$, which are about three time lower than the values found before conservation, meaning that cheeses became less creamy.

Stickiness of cheeses was found to be quite different before storage in different conditions, -2.62 and $-2.82 \mathrm{~N}$ for Control and Frozen cheeses, respectively. The stickiness of cheeses presented a great decrease after 120 days of storage, being the cheeses also less creamy. However, the Frozen cheese presented a high value of stickiness, $0.76 \mathrm{~N}$, comparing with the control one.

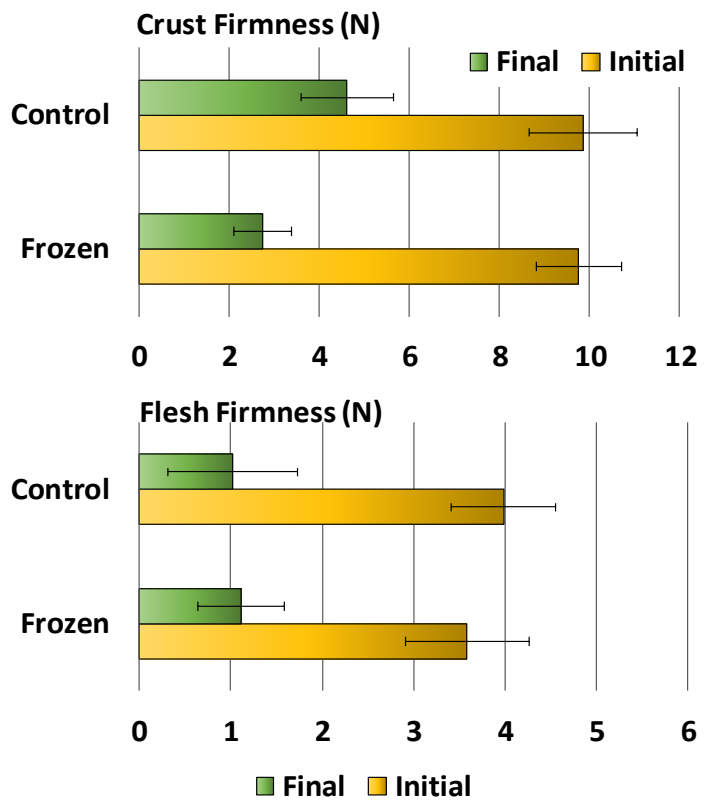

\section{Stickiness (N)}

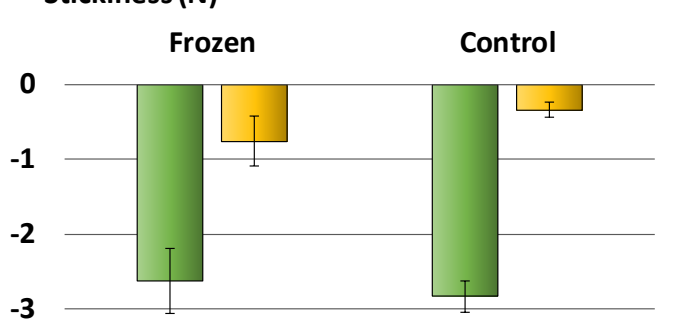

$-4$

Adhesiveness (N.sec)

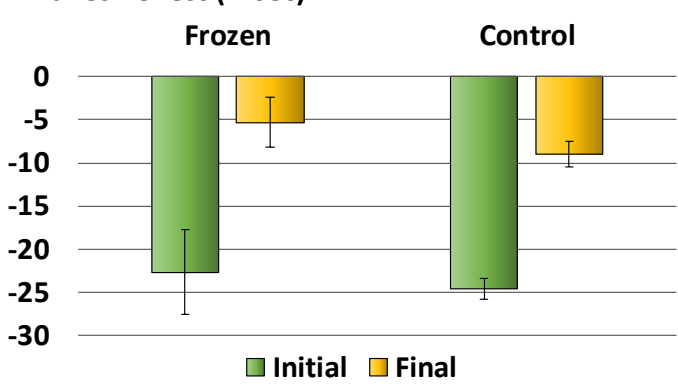

Figure 7. Textural characteristics of cheeses in the initial and final stage of storage.
The results showed in Fig. 7 indicate that the adhesiveness of the cheeses in the initial stage of storage was similar, -22.7 N.sec (Frozen cheese) and -24.7 N.sec (Control cheese), and during the 120 days of storage this textural characteristic diminishes about three times, meaning that the cheeses became less soft and creamy.

The texture of cheese depends on composition (moisture, protein, fat and mineral content), $\mathrm{pH}$ of the curd and ripening conditions and temperature, as well as the microbial contamination throughout the mass and the surface of the cheese [20], but also of the conservation processes.

\section{CONCLUSIONS}

This work focused on the evaluation of some physical properties of ewe's cheese subject to freezing process and the changing of its characteristics during storage, in comparison with a cheese submitted to the usual commercial storage for 120 days.

The results obtained allowed verifying that in fact when frozen cheeses were submitted to short time storage, they physical properties were quite like cheeses subject to refrigeration temperatures. However, the storage time have a greatly influence on the physical characteristics of cheeses. After 120 days of storage, cheeses diverged importantly among samples, and the biggest differences between the two conservation processes were in the moisture content, stickiness and adhesiveness. The frozen cheeses presented a high moisture content and stickiness, but low adhesiveness. Generally, cheeses became drier, darker and less yellow, on the other hand the textural properties related to the creaminess of the paste, adhesiveness and stickiness were less intense.

Thus, for future works it is important to study deeply the effect of low temperatures in ewe's cheese characteristics, determine and optimal freezing storage, thawing, and aging combination for these cheeses, and no less important investigate the factors that contribute to the physical changes of this foodstuff.

\section{ACKNOWLEDGMENT}

This work is financed by national funds through FCT Fundação para a Ciência e Tecnologia, I.P., under the project UID/Multi/04016/2016. Furthermore, we would like to thank the Instituto Politécnico de Viseu and CI\&DETS for their support.

\section{REFERENCES}

[1] F. K. Tavaria, I. Franco, F. J. Carballo, and F. X. Malcata, “Amino acid and soluble nitrogen evolution throughout ripening of Serra da Estrela cheese," International Dairy Journal, vol. 13, no. 7, pp. 537-545, 2003.

[2] R. C. Rodrigues, J. C. Almeida, C. D. Pereira, D. S. Gomes, J. P. Madanelo, M. J. Oliveira, and M. L. Fonseca, Queijo Serra da Estrela Processos Tradicionais e Inovações Tecnológicas, Coimbr: Direcção Regional de Agricultura da Beira Litora, 2000.

[3] P. J. M. Reis and F. X. Malcata, "Ripening-related changes in Serra da Estrela cheese: A stereological study," Journal of Dairy Science, vol. 94, no. 3, pp. 1223-1238, 2011.

[4] A. C. Macedo, T. G. Tavares, and F. X. Malcata, "Influence of native lactic acid bacteria on the microbiological, biochemical and 
sensory profiles of Serra da Estrela cheese," Food Microbiology, vol. 21, no. 2, pp. 233-240, 2004.

[5] J. Fuquay, P. Fox, and P. McSweeney, Encyclopedia of Dairy Sciences, 2nd ed., United Kingdom: Elsevier Academic Press, 2011.

[6] S. Gunasekaran and M. M. Ak, Cheese Rheology and Texture, New York: CRC Press, 2002.

[7] P. C. Moreira, "Desenvolvimento de metodologias analíticas para queijos- Estudo de caso: Queijos da Beira Interior,” Dissertação para obtenção do grau de Mestre em Engenharia Alimentar, Instituto Superior de Agronomia da Universidade Técnica de Lisboa, 2011.

[8] M. I. Kuo and S. Gunasekaran, "Effect of frozen storage on physical properties and nonpasta Filata Mozzarella cheeses," Journal of Dairy Science, vol. 86, pp. 1108-1117, 2003.

[9] N. C. Bertola, A. E. Califano, A. E. Bevilacqua, and N. E. Zaritzky, "Effect of freezing conditions on functional properties of low moisture Mozzarella cheese," Journal of Dairy Science, vol. 29, pp. 185-190, 1996.

[10] H. A. Diefes, S. S. H. Rizvi, and J. A. Bartsch, "Rheological behaviour of frozen and thawed low-moisture, part-skim Mozzarella cheese," Journal of Food Science, vol. 58, pp. 764-769, 1993.

[11] K. Kasprzak, "The effect of fat, moisture, and salt on the freezing qualities of Cheddar-type cheeses," M. S. thesis, University of Wisconsin-Madison, USA, 1992.

[12] C. J. Oberg, R. K. Merrill, R. J. Brown, and G. H. Richardson, "Effects of freezing, thawing, and shredding on low moisture, part-skim Mozzarella cheese," Journal of Dairy Science, vol. 75, pp. 1161-1166, 1992.

[13] I. Pantaleão, M. M. E. Pintado, and M. F. F. Poças, "Evaluation of two packaging systems for regional cheese," Food Chemistry, vol. 102, pp. 481-487, 2007.

[14] N. B. M. G. Alvarenga, "Introdução da tecnologia de congelação na produção de queijos de ovelha," Doutoramento em Engenharia Agro-Industrial, Instituto Superior de Agronomia da Universidade Técnica de Lisboa, 2008.

[15] M. Mushtaq, A. Gani, P. H. Shetty, F. A. Masoodi, and M. Ahmad, "Himalayan cheese (Kalari/ Kradi): Effect of different storage temperatures on its physicochemical, microbiological and antioxidant properties," LWT-Food Science and Technology, vol. 63, pp. 837-845, 2015.

[16] A. Rawson, A. Koidis, A. Patras, M. G. Tuohy, and N. P. Brunton, "Modelling the effect of water immersion thermal processing on polyacetylene levels and instrumental colour of carrot disks," Food Chemistry, vol. 121, pp. 62-68, 2010.

[17] R. Saurel, A. Pajonk, and J. Andrieu, "Modeling of French Emmental cheese water activity during salting and ripening periods," Journal of Food Engineering, vol. 63, pp. 163-170, 2004

[18] C. J. F. Neto, R. M. F. Figueiredo, and A. J. M. Queiroz, "Sensory evaluation and water activity of the seasoned cassava flour," Lavras, vol. 29, pp. 795-802, 2005.

[19] P. M. R. Correia, et al., "Influence of different process parameters in physical and sensorial properties of Serra da Estrela cheese," Journal of Hygienic Engineering and Design, vol. 8, pp. 135-140, 2014.

[20] R. P. F. Guiné, M. I. C. Tenreiro, A. C. Correia, P. M. R. Correia, and P. Barracosa, "Analysis of factors influencing the physical, chemical and sensorial properties of Serra da Estrela cheeses," Food Measure, vol. 10, pp. 643-657, 2016.

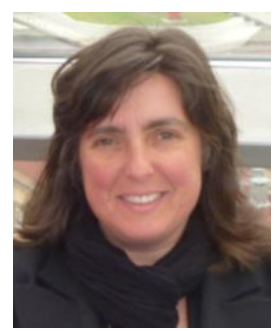

Paula Correia born in Morfortinho, Portugal, on $17^{\text {th }}$ of April 1967. She is graduated in Agro-Food Engineering (1992), Master's degree in Food Science and Technology (1996), and doctor in Food Engineering (2011), all by University of Lisbon, Portugal. Experience in food science and technology field, mainly in food conservation and processing; cereal and starch technology; food drying; food quality and safety; food composition and analysis.

She is a professor in Agrarian High School of Polytechnic Institute of Viseu, Portugal, and also a researcher in the Agrarian, Food and Veterinary Sciences group in the research center CI\&DETS (Viseu, Portugal). She was the institutional leader of one international project, COMPASS (Leonardo da Vinci transfer of innovation project), and two national projects, AGRO 448 and ValNuts, PDR2020. She also participated in other $2 \mathrm{EU}$ and 6 national projects. She is author/coauthor of 5 books, 6 book chapters, 39 papers in peer-reviewed journals (h-index 10, 413 citations by 273 documents) and more than 60 papers in conferences. She is a co-editor of 1 book. She has experience in supervision of Master students (10 finished, 2 in progress). She has been member of the Editorial boarder of Millenium- Journal of Education, Technologies, and Health. She is a regular Referee of several scientific journals. (http://orcid.org/0000-0002-2023-4475). Prof. Correia is a member of ISHS (International Society of Horticulture Science), and Portuguese Engineer Order and Portuguese Chemical Society. 